\title{
Late-Summer Feeding and Migration Behaviour and Numerical Trends of Common Nighthawks, Chordeiles minor, near Pinawa, Manitoba, 1976-2009
}

\author{
PETER TAYLOR
}

Box 597, Pinawa, Manitoba R0E 1L0 Canada; e-mail: taylorp@granite.mb.ca

Taylor, Peter. 2009. Late-summer feeding and migration behaviour and numerical trends of Common Nighthawks, Chordeiles minor, near Pinawa, Manitoba, 1976-2009. Canadian Field-Naturalist 123(4): 338-345.

Feeding concentrations of Common Nighthawks, Chordeiles minor, during the evening in late summer were observed and counted near the Pinawa, Manitoba, sewage lagoons during 28 of the 34 years from 1976 to 2009. Counts were frequent but non-systematic in 1976-1981, infrequent in 1982-1991, and both frequent and systematic in most years during the period 1992-2009. Results of 226 counts are analysed and interpreted as showing a major decline in the local breeding population during the 1980s but more stable numbers of transient birds, assumed to originate farther north. The timing and other characteristics of feeding and migratory behaviour are discussed. The limitations of interpreting data from a single location are acknowledged and some systematic survey methods are recommended, emphasizing the importance of all-round, longrange visibility to help distinguish between migration and foraging.

Key Words: Common Nighthawk, Chordeiles minor, threatened species, autumn migration, aerial insectivores, Manitoba.

The Common Nighthawk (Chordeiles minor) is one of several aerial insectivores that are declining in numbers, especially in northeastern North America (Sandilands 2007; Conservation Committee of the Society of Canadian Ornithologists-Société des ornithologistes du Canada 2009). It was designated a threatened species in April 2007 by the Committee on the Status of Endangered Wildlife in Canada (COSEWIC), based on evidence of decline from many sources, including Breeding Bird Survey (BBS) data (Savignac and Leonard 2007). Recent declines in Ontario, based on Breeding Bird Atlas data collected in 1981-1985 and 2001-2005, were most pronounced in the southern Canadian Shield region, but were significant in all regions of the province except the Hudson Bay Lowlands (Sandilands 2007). Data were admittedly sparse in the latter region.

I have previously reported results of surveys of Common Nighthawks during fall migration near the Pinawa sewage lagoons $\left(50^{\circ} 8^{\prime} \mathrm{N}, 95^{\circ} 55^{\prime} \mathrm{W}\right)$, about $100 \mathrm{~km}$ eastnortheast of Winnipeg, Manitoba (Taylor 1996). Those surveys showed a marked drop in numbers from the late 1970 s to the early 1990 s. This was based on frequent but non-systematic counts of feeding concentrations in 1976-1981 (52 dates, including 19 during the peak period, 11-25 August), infrequent counts in 1982-1991 (14 dates, including 9 during the peak period), and systematic counts in 1992-1995 (56 dates, including 33 during the peak period).

This update incorporates further systematic counts on 104 dates, including 74 during the peak period, in 1996-2009 (except 1998, 1999, 2003, and 2004), plus incidental observations elsewhere in southeastern Manitoba. While year-to-year numerical trends are still of interest, attention was also paid to the timing of feed- ing concentrations, the distinction between migrating and feeding flocks, and the foraging strategy exhibited by feeding flocks. The limitations of interpreting numbers at a single location are recognized, but some patterns are detected and some general recommendations made for Common Nighthawk surveys.

\section{Methods}

Common Nighthawks were counted around sunset, primarily during the second to fourth weeks of August. The relatively open setting of the sewage lagoons within a mostly forested area gives an uninterrupted view in all directions, except when birds are flying near or below treetop height (Taylor 1996). Birds were counted by 360-degree binocular scans at intervals of about two minutes, starting with either my arrival (if Common Nighthawks were already active) or the appearance of the first birds, and continuing until either the birds dispersed or (more often) poor light prevented accurate counting.

Counting periods varied from about 20 minutes (timed to coincide with the normal feeding peak at dusk) to 2 hours (ending at dusk), usually 30 minutes to 1 hour. It was often possible to extend the counting period by walking around the lagoons until the main feeding flock was silhouetted in the western sky. For counts since 1995, the position of flocks (distance and direction relative to the three lagoons and approximate altitude) was noted, as were the weather conditions, including approximate wind speed and direction.

So long as birds remained above the treetops, exact counts were usually possible for loose flocks of up to 20 Common Nighthawks, and counts were repeatable within about 5\% for flocks of 20 to 100 birds. Counting larger numbers became increasingly difficult, with 


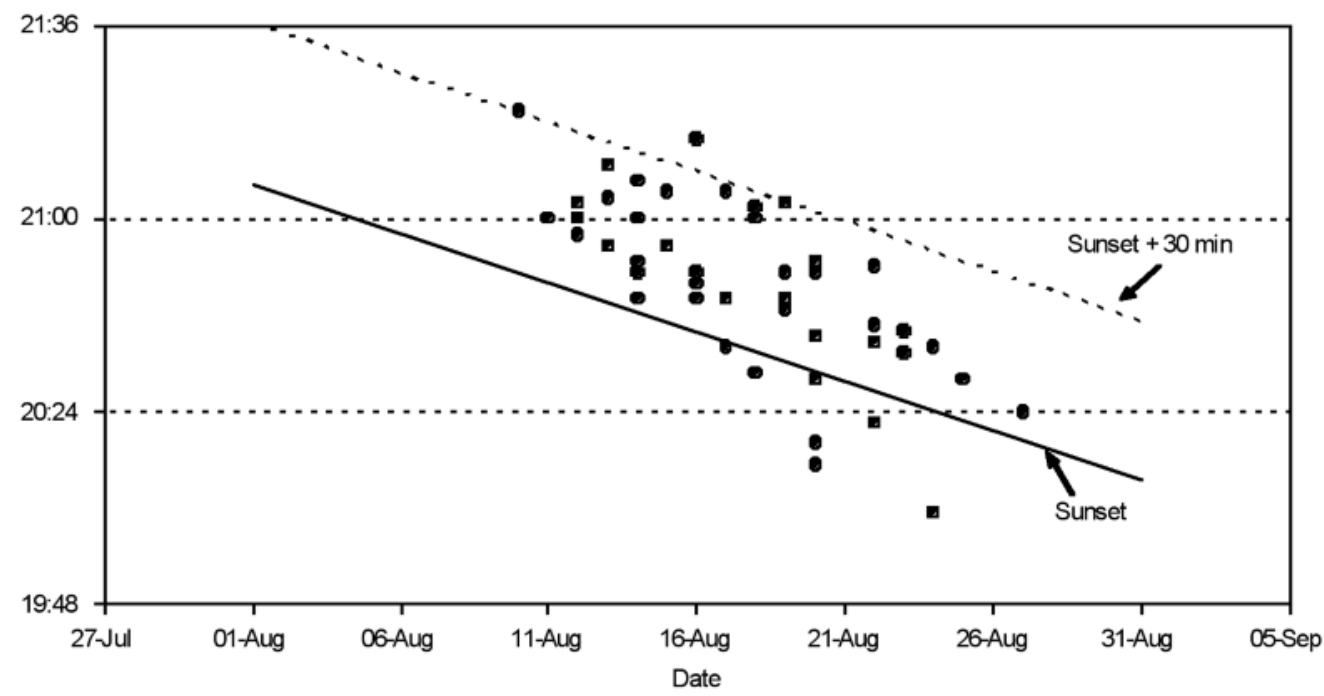

FIGURE 1. Time of peak counts of Common Nighthawks at Pinawa, Manitoba, sewage lagoons, 1994-2008. Data are shown for 47 counts of at least 20 birds, and only for counting periods long enough to show a well-defined peak.

an estimated uncertainty of $10-20 \%$ for flocks in the $150-300$ range.

\section{Results and Discussion}

Feeding concentrations occurred regularly, with tallies of at least 10 Common Nighthawks in 70 of the 101 counts in 1996-2009 and in 74 of the 105 counts in 1976-1995. Zero totals were recorded just 14 times in the systematic counts (1992-2009) and only 3 times between 11 and 25 August, inclusive; they were not always recorded before 1992 .

Common Nighthawks were rarely sufficiently close and well lit to distinguish between adult males, adult females, and immature birds (based on throat and tail patterns, as illustrated by Sibley (2000)), so age and sex data were not available. The characteristic peent calls were heard only occasionally from both migrating and feeding flocks.

\section{Timing of feeding flocks}

The first birds often arrived during the 15 minutes before sunset, around 20:30, but sometimes well before 19:00. [All times are reported as Central Daylight Time. Observations refer to official sunset times, which were about 5 minutes later than effective sunset below a distant tree-line.] Numbers usually reached a peak during the half hour after sunset, but sometimes a little before sunset, especially after 15 August (Figure 1). The activity of Common Nighthawks was visible up to $20-40$ minutes after sunset, depending on cloud cover and the location of the birds. Post-feeding dispersal was difficult to observe, because of reduced light intensity, but numbers usually declined noticeably before light failed.
Comparable observations were reported by Brigham and Fenton (1991) on foraging flocks of Common Nighthawks from a breeding population along the Okanagan River, British Columbia, in 1985-1987. On average, they observed Common Nighthawks foraging from 28 minutes before sunset to 68 minutes after sunset. Individual birds fitted with radio transmitters averaged 48 minutes of foraging at dusk (Brigham and Fenton 1991). Slightly different times are given by Aldridge and Brigham (1991). That study also included observations of dawn feeding activity, which is of shorter duration.

\section{Behaviour of feeding flocks}

Towards sunset in August, Common Nighthawks typically arrive at the Pinawa sewage lagoons singly or in small groups, sometimes at relatively high altitude (over $100 \mathrm{~m}$ ), and mostly from the north. It is impossible to say from whence they come, but I have the impression that at least some stage in the area and visit the lagoons from individual roosting sites nearby, whereas others may pause to feed near the lagoons at the end of a migration leg. Groups and scattered individuals gradually form up into one or two loose feeding flocks. Although the flight of individuals seems erratic, these flocks occupy a well-defined volume of airspace.

In moderate winds $(10-30 \mathrm{~km} / \mathrm{h})$, the flocks commonly form well above treetop height (20-50 m above ground) and up to $500 \mathrm{~m}$ downwind of the most southwesterly of the three lagoons, which is a focus of their activity. Within the flock, foraging birds tend to fly slowly into the wind, veering aside from time to time in pursuit of prey, then wheeling back swiftly when 
they reach the limit of the foraging space. As darkness falls, the wind speed usually declines, and the Common Nighthawks tend to forage lower and closer to the lagoon, until towards last light they are concentrated directly over the lagoon and often flying within a metre of the water's surface.

In strong winds (> $30 \mathrm{~km} / \mathrm{h}$ ) the Common Nighthawks, if present at all, gather low over the treetops. In light winds $(<10 \mathrm{~km} / \mathrm{h})$ they still form feeding flocks, but the location is less predictable with respect to wind direction.

Common Nighthawks thus appear to exploit a plume of flying insects emerging from the lagoon, starting at the downwind end of the plume and finishing at the source and perhaps benefiting from reflected light from the water as ambient light levels fall. As noted by Aldridge and Brigham (1991), Common Nighthawks (unlike bats, Eptesicus fuscus) are able to forage only when there is some illumination. Brigham and Fenton (1991) observed that, at both dusk and dawn, Common Nighthawks began foraging bouts above treetop height $(>30 \mathrm{~m})$, then gradually foraged at lower altitudes, eventually flying less than $0.5 \mathrm{~m}$ above the surface of the river before departing. Since light intensity increases at dawn and decreases at dusk, this behaviour seems to have more to do with systematic exploitation of an insect swarm than with illumination levels.

At times the Common Nighthawks concentrate elsewhere within sight of the lagoons, presumably wherever insect prey numbers are highest on a given evening. Birds often move back and forth between feeding flocks. During August of 2007, 2008, and 2009, Common Nighthawks paid less attention than usual to the southwestern lagoon, perhaps because major blooms of duckweed (Lemna sp.) and algae there had reduced insect productivity. Overall Common Nighthawk numbers were also low in those three years. A change in lagoon management practice during the 1990s, with reduced draw-down of water levels, may also have affected prey productivity in recent years. I have fewer systematic data on other insect-eating birds at the lagoons. Swallow numbers (mostly Barn Swallows, Hirundo rustica) held up well from the late 1970s to the mid-1990s (Taylor 1996), but concentrations now seem more sporadic than formerly. Bonaparte's Gull (Chroicocephalus philadelphia), Black Tern (Chlidonias niger), and Red-necked Phalarope (Phalaropus lobatus), all of which feed on insects on and/or above the lagoons, are also less numerous now than in the 1970s and 1980s (Taylor 1983, 1993).

Common Nighthawks feed on small insects that are rarely visible with binoculars, let alone identifiable. The birds appear to ignore concentrations of dragonflies (mostly darners, Aeshna spp.) that sometimes hunt near the lagoons in large numbers around sunset, consistent with observations in Minnesota (Eckert and Hendrickson 1991). Numbers of Common Nighthawks did not vary systematically with the subjective nuisance level of mosquitos. Huge numbers of flies (possibly small chironomids) emerging from one of the lagoons on 16 August 1997 attracted an unusually large feeding flock of about 150 Common Nighthawks. In the Okanagan River study, Common Nighthawks showed a strong preference for caddisflies (Trichoptera) and flying ants (Formicidae), but tended to ignore chironomids (Brigham 1990).

\section{Timing of migrating flocks}

Flocks that were obviously migrating were observed less frequently than foraging flocks; migrating flocks were typically seen or reported to me on no more than three days per season, often over the town of Pinawa or elsewhere in the area. They were most often seen between 18:00 and 19:30, and occasionally earlier in the day. Concentrations of 25 or more birds were noted on dates from 12 August to 1 September, with about $75 \%$ of reports between 17 and 26 August, inclusive. Reto Zach counted 152 Common Nighthawks migrating over Pinawa in five minutes on the evening of 17 August 1997. [Observations cited without published references were obtained by personal communication or indirect correspondence.] He also noted a strong movement on 21 August 2001, with some flocks moving steadily, starting around 18:00, and a foraging flock of 65 birds later in the evening.

This situation is comparable to observations at Duluth, Minnesota, where concentrations of Common Nighthawks in August have occasionally exceeded 10000 birds (Eckert 1986; Eckert and Hendrickson 1991; Nicoletti 1997). Major flights there occurred between 14 and 27 August, inclusive, usually on days with above-normal temperatures and light winds, starting in late afternoon and ending or slowing down about one-half to one hour before sunset (Eckert and Hendrickson 1991). Morning as well as afternoon flights have been observed at Hawk Ridge, near Duluth (Nicoletti 1997).

\section{Behaviour of migrating flocks}

Migrating Common Nighthawks usually fly in a constant direction, without deviating to pursue insects, as noted by Brigham and Fenton (1991) for day-flying individuals in general. Not all flocks of Common Nighthawks, however, fit neatly into a feeding or migrating category. Some flocks pass the Pinawa lagoons around sunset without stopping, whether or not a feeding flock is already present: are they migrating or just heading for a different feeding area? A good example involving large numbers took place on 24 August 2000. Whereas 96 Common Nighthawks were seen between 20:30 and 20:50, the feeding flock never exceeded 18 birds. Another 62 passed high over the lagoons in a south-southeasterly direction without feeding, and another 16 flew steadily eastward, hawking for insects as they went.

Between 18:00 and 19:30 on 24 August 1997, I watched a movement of at least 30 Common Night- 


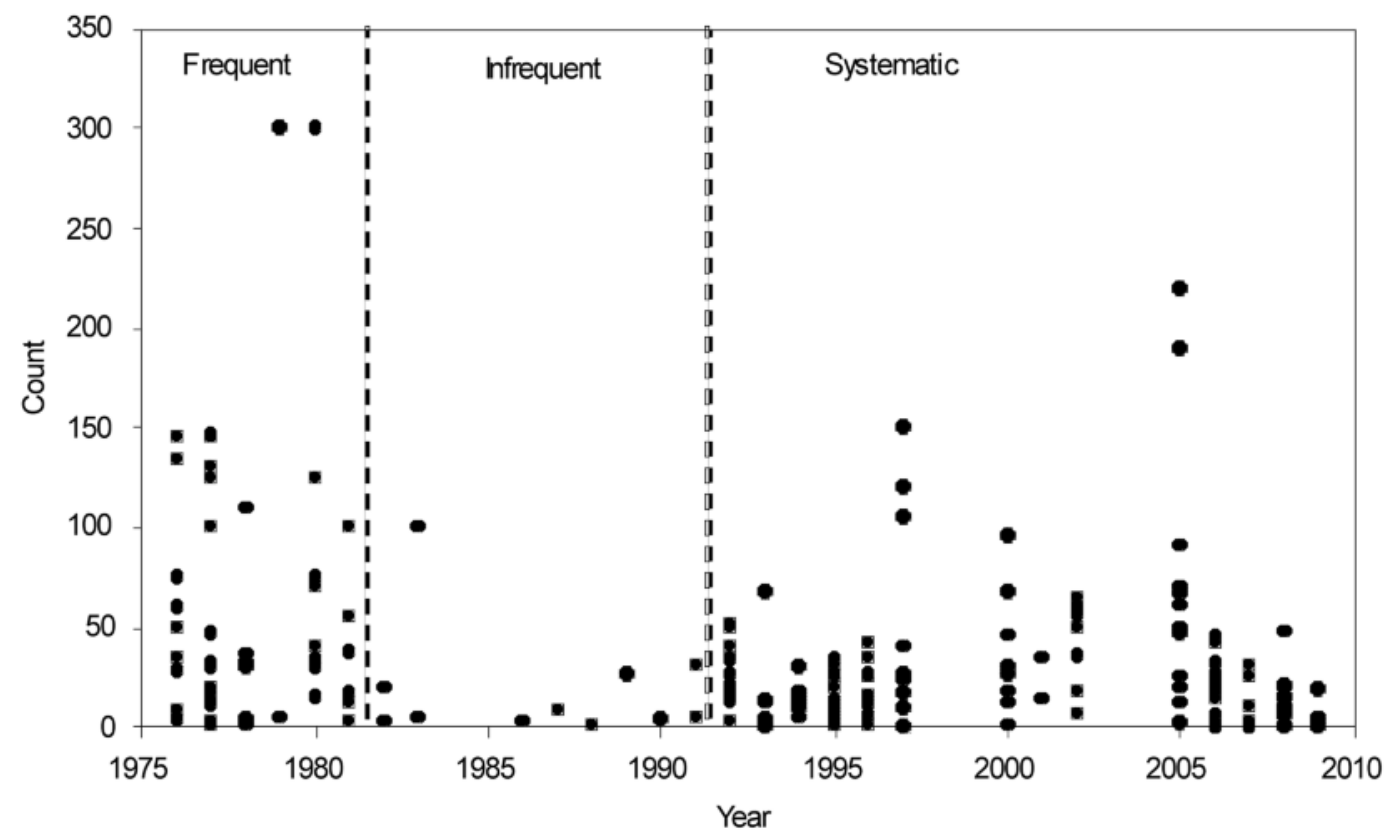

FIGURE 2. Compilation of all counts of Common Nighthawks at Pinawa, Manitoba, sewage lagoons, 1976-2009, sorted by year. Vertical dashed lines separate the three phases of the data collection.

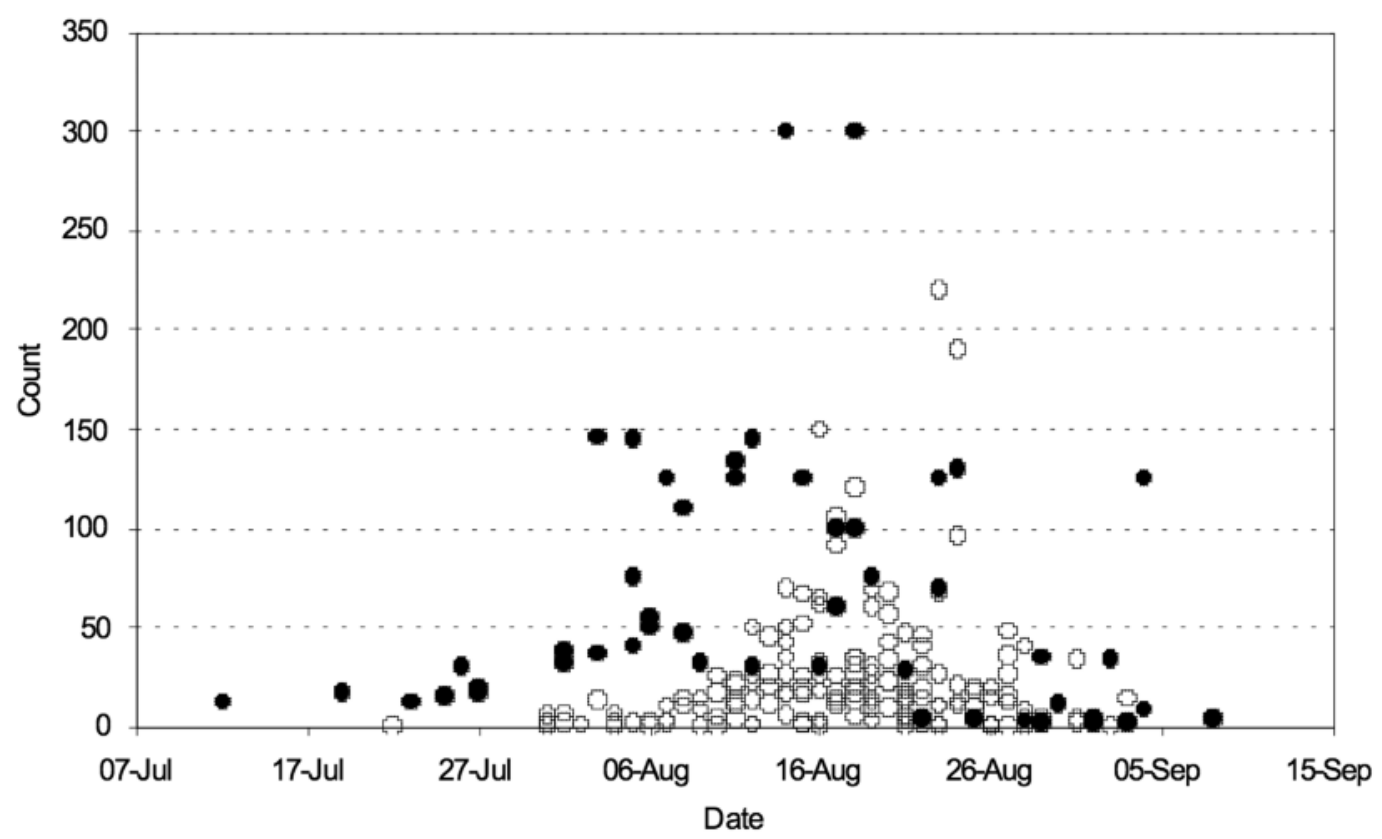

FIgURE 3. Compilation of counts of Common Nighthawks at Pinawa, Manitoba, sewage lagoons, for selected periods, sorted by date. Filled circles, 1976-1981; open circles, 1992-2009. 
TABLE 1. Summary of Common Nighthawk counts at Pinawa, Manitoba sewage lagoons, 1976-2009.

\begin{tabular}{|c|c|c|c|c|c|c|c|c|}
\hline \multirow[b]{2}{*}{ Year } & \multirow[b]{2}{*}{ Earliest } & \multirow[b]{2}{*}{ Latest } & \multicolumn{2}{|c|}{ Number of counts } & \multicolumn{2}{|c|}{ Maximum count } & \multicolumn{2}{|c|}{ August counts only } \\
\hline & & & $\overline{\text { All }}$ & $\overline{11-25 \text { August }}$ & Number & $\overline{\text { Date (August) }}$ & Mean & $\overline{S D}$ \\
\hline 1976 & 5 August & 8 September & 10 & 4 & 145 & 12 & 75 & 48 \\
\hline 1977 & 12 July & 3 September & 18 & 6 & 146 & 5 & 82 & 56 \\
\hline 1978 & 3 August & 1 September & 7 & 3 & 110 & 8 & 36 & 35 \\
\hline 1979 & 14 August & 22 August & 2 & 2 & 300 & (14) & - & - \\
\hline 1980 & 25 July & 4 September & 8 & 3 & 300 & (18) & - & - \\
\hline 1981 & 23 July & 3 September & 7 & 1 & 100 & (18) & - & - \\
\hline 1982 & 23 August & 30 August & 2 & 1 & 20 & (30) & - & - \\
\hline 1983 & 10 August & 22 August & 4 & 3 & 100 & (22) & - & - \\
\hline 1986 & 12 August & 25 August & 2 & 2 & 3 & $(12,25)$ & - & - \\
\hline 1987 & 12 August & 12 August & 1 & 1 & 8 & (12) & - & - \\
\hline 1988 & 14 September & 14 September & 1 & 0 & - & - & - & - \\
\hline 1989 & 10 August & 10 August & 1 & 0 & 26 & (10) & - & - \\
\hline 1990 & 29 August & 29 August & 1 & 0 & 4 & (29) & - & - \\
\hline 1991 & 21 August & 23 August & 2 & 2 & 31 & (21) & - & - \\
\hline 1992 & 7 August & 3 September & 11 & 6 & 52 & 15 & 29 & 15 \\
\hline 1993 & 10 August & 28 August & 7 & 5 & 68 & 23 & 19 & 23 \\
\hline 1994 & 15 August & 24 August & 10 & 10 & 30 & 22 & 13 & 7 \\
\hline 1995 & 31 July & 1 September & 28 & 12 & 34 & 20 & 10 & 9 \\
\hline 1996 & 9 August & 29 August & 13 & 9 & 42 & 20 & 17 & 12 \\
\hline 1997 & 22 July & 25 August & 14 & 10 & 150 & 16 & 46 & 47 \\
\hline 2000 & 17 August & 26 August & 8 & 7 & $96 \dagger$ & 24 & 37 & 30 \\
\hline 2001 & 14 August & 22 August & 2 & 2 & 35 & (14) & - & - \\
\hline 2002 & 4 August & 27 August & 7 & 5 & 65 & 16 & 42 & 21 \\
\hline 2005 & 10 August & 29 August & 13 & 10 & 220 & 23 & 71 & 63 \\
\hline 2006 & 31 July & 26 August & 14 & 11 & 45 & 13 & 21 & 14 \\
\hline 2007 & 7 August & 28 August & 11 & 6 & 31 & 22 & 7 & 11 \\
\hline 2008 & 6 August & 28 August & 13 & 9 & 48 & 27 & 13 & 12 \\
\hline 2009 & 1 August & 2 September & 9 & 5 & 19 & 15,22 & 7 & 7 \\
\hline
\end{tabular}

$\dagger$ Mostly passing birds (see text); next highest, 68 on 20 August 2000.

NOTE: For years with fewer than five August counts, mean and standard deviation (SD) are not given and peak dates are shown in parentheses. The high SD values are of limited use, because they reflect sampling throughout the migration period, including low numbers in the early and late stages, as well as day-to-day fluctuations.

hawks over the town of Lac du Bonnet (about $20 \mathrm{~km}$ northwest of Pinawa). They flew erratically, with much circling and backtracking, unlike the direct flight of most migrating birds. Perhaps they were assessing the insect supply for an evening feed after a leg of their migration. Similarly, on or about 20 August 1987, an evening flock of about 60 Common Nighthawks over Pinawa seemed to be in transition between migration and feeding.

At about 19:00 on 27 August 2008, Reto Zach and I observed a loose flock of at least 34 Common Nighthawks flying southward over a large marsh in the Pinawa Channel, about $3 \mathrm{~km}$ north of the sewage lagoons. Although the flock was making steady progress, some birds paused to forage briefly above the marsh before continuing on their way. A concentration of 48 Common Nighthawks at the lagoons at 20:20 the same evening (the highest count of the year) may well have included these birds.

On 12 August 2005, Sharon Taylor and I were watching a feeding flock of about 50 Common Nighthawks at the Pinawa lagoons when a brief rain squall passed through from the west. Most birds continued feeding during the squall. At 21:15, after the squall had passed, a concentrated group of 33 birds quickly disappeared in direct, purposeful flight east-southeast, seeming to take advantage of favourable winds behind the squall line. Other observers have mentioned that flocks of Common Nighthawks sometimes appear just before or after thunderstorms (R. Tuokko, M. Zach, N. Bremner, personal communication).

On 21 August 2005, I watched 32 feeding Common Nighthawks abruptly gather into a tighter group and swiftly fly more than $1 \mathrm{~km}$ to the east-southeast. They then paused, broke formation, and gradually straggled back to re-form a feeding flock over the lagoons, the urge to feed apparently overcoming the urge to migrate. Feeding conditions were apparently good that year, because a few nights later I recorded the largest flocks since 1980: an estimated 220 on 23 August 2005 and 190 the following evening. This example, and several other cases of high counts on two or three consecutive evenings, support the idea that migrating flocks sometimes stage in the area for a few days. 


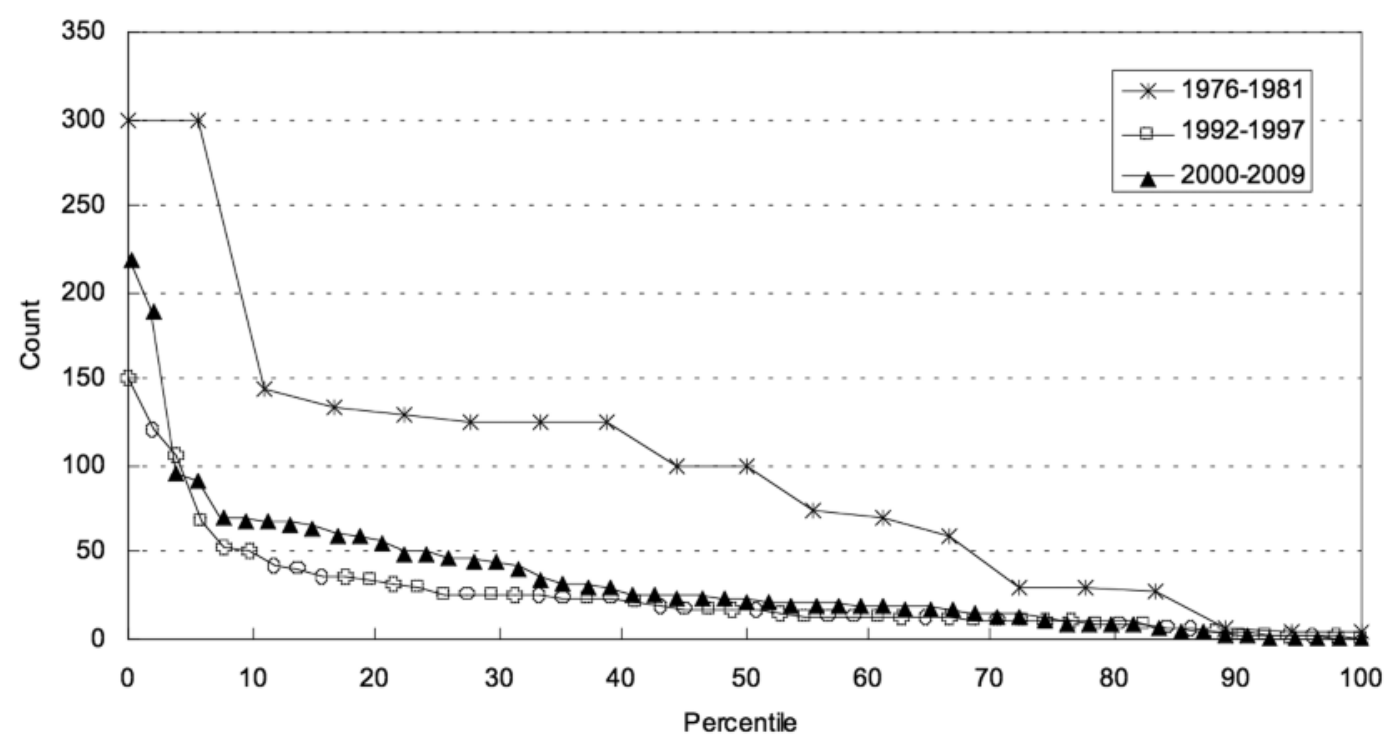

FIGURE 4. Distribution of count values for 11-25 August, expressed as percentiles for the periods 1976-1981 (asterisks), 1992-1997 (open circles), and 2000-2009 (solid triangles). Highest value $=0$ percentile, lowest value $=100$ percentile, all other values are shown in descending order.

\section{Numerical trends and fluctuations}

Count data are summarized in Table 1. Tallies of Common Nighthawks from all 226 counts over the 34-year period of this study are shown graphically in Figure 2 (sorted by year) and Figure 3 (sorted by date). Figure 3 discriminates between early (1976-1981, filled circles) and more recent counts (1992-2009, open circles), and excludes the sparse data for 1982-1991. Figure 4 compares the distribution of count values for the peak migration period from 11 to 25 August, expressed as percentiles, and pooled for the time intervals 1976-1981, 1992-1997, and 2000-2009.

The numbers of Common Nighthawks show strong day-to-day and year-to-year fluctuations, making analysis difficult; simple trend analyses can be strongly influenced by a single high year, such as 2005 (Figure 2). Similarly, huge fluctuations in numbers have been noted in the large August concentrations near Duluth, Minnesota (Eckert 1986; Eckert and Hendrickson 1991; Nicoletti 1997). The fluctuations are presumably linked to weather patterns prompting the birds to migrate or concentrate, local factors (especially insect availability) prompting them to linger or not, and the condition of the birds (e.g., fat reserves on arrival in the Pinawa area), as well as year-to-year variations in the source population's size and breeding productivity.

For the period 31 July to 11 August, all 1976-1981 counts were considerably higher than all subsequent counts on corresponding dates, whereas counts for the balance of August are less obviously discriminated
(Figure 3). It is plausible that the early August flocks in 1976-1981 were pre-migratory concentrations of local breeding birds and that the counts between midAugust and late August involved a higher proportion of transients, originating farther north. A local contingent was also likely responsible for the significant counts (12 to 30 birds) recorded between mid-July and late July in 1977, 1980, and 1981 (Figure 3). Unfortunately, there are few July data for later years (Table 1). Common Nighthawks apparently disappeared as breeding birds in Pinawa in the early 1980s, although some doubtless continue to breed elsewhere in the region, e.g., in Whiteshell Provincial Park and Nopiming Provincial Park (Taylor 1996). In the Okanagan study, Brigham and Fenton (1991) observed regular feeding flocks of 200-300 Common Nighthawks, presumably local breeders, from early June to midJuly, with numbers declining to 50 or fewer by midAugust. This is consistent with some post-breeding movements occurring before the main migration peak.

Fluctuations in numbers can be smoothed by pooling data for the three periods: 1976-1981, 1992-1997, and 2000-2009. This was done to prepare Figure 4, which is limited to counts during the nominal peak migration period, 11-25 August.[Some of these data were previously published (Taylor 1996).] This period was identified in the earlier study, and it was used to focus systematic survey effort (Taylor 1996). In retrospect, it may be a few days too early and the 15day window may perhaps be too restrictive; nevertheless, in most years it appears to capture the main 
TABLE 2. Reports of Common Nighthawk flocks exceeding 100 birds in Manitoba (except Pinawa townsite and sewage lagoons) since 1995.

\begin{tabular}{lllll}
\hline \hline Date & Number & Observer & Location & $\begin{array}{l}\text { Direction and distance } \\
\text { from Winnipeg }\end{array}$ \\
\hline 21 August 1998 & $200+$ & A. Walleyn & Holland & 130 km west-southwest \\
23 August 2000 & $100+$ & R. Tuokko & Pinawa Lake & $130 \mathrm{~km}$ northeast \\
24 August 2000 & 224 (several flocks) & D. Fast & Manigotagan to Stead & 140 to 80 km northeast \\
21 August 2001 & $200+$ & P. Goossen & Falcon Lake & 100 km east-southeast \\
\hline \hline
\end{tabular}

migration peak. When the distribution of all count data is depicted, there is still a clear discrimination between high counts in 1976-1981 and markedly lower counts in subsequent years (Figure 4). This is illustrated dramatically if we consider the number of tallies of 100 or more birds $-50 \%$ of the counts and 5 out of 6 years in 1976-1981 had 100 or more birds, but only $5 \%$ of the counts and 2 out of 14 years in 1992-2009 achieved that number.

The main difference between the 1992-1997 and 2000-2009 count distributions lies between the 5th and 35 th percentiles (Figure 4), reflecting some high counts in three of the eight years sampled: 2000, 2002, and 2005 (Figure 2). The patterns shown in Figure 4 are again consistent with a decline in Common Nighthawks during the 1980s (possibly involving mainly local birds) but a more stable source population of transient birds, whose origin is unknown but could be far north of the Pinawa area (or northwest, given the often easterly drift of their movements). In turn, this is consistent with the suggestion of pronounced declines in the southern Canadian Shield region of Ontario but more stable numbers in the Hudson Bay Lowlands region (Sandilands 2007).

\section{Observations elsewhere in Manitoba}

In October 2000, the late Norm Cleveland sent me a list of 36 counts of Common Nighthawks made during the evening in August from his home in the Niakwa Park area of Winnipeg, about $1.5 \mathrm{~km}$ east of the Red River, in 28 years between 1968 and 2000, inclusive. On 30 August 1973, he noted "large numbers, afternoon and evening". Numbers were particularly high in the early 1980 s, with five counts of more than 100 birds in 1980-1983 and a peak of 325 on 20 August 1981. His only other three-figure total was an estimate of 100 on 28 August 1992; only single-digit numbers were observed in subsequent years. The 17 highest counts (of at least 20 birds) occurred between 14 and 31 August, inclusive, with only two of these 17 counts being later than 1984. The relative contributions of urban breeders and transients to these former concentrations is unknown, but the peak dates suggest mainly transients. Other Winnipeg birders concur in the near-disappearance of late-summer concentrations of Common Nighthawks from the city's skies, although Gordon Grieef reported a count of 255 migrants as recently as 25 August 1991.
Several anecdotal reports of large concentrations of Common Nighthawks elsewhere in Manitoba, mostly in August, up to 1995, were summarized previously (Taylor 1996). Of particular interest, two pairs of counts indicate widespread one-day movements: 1300 at Delta (P. Grieef) and 500+ between Beausejour and Pinawa (R.F. Koes) on 23 August 1993; 625 at Stonewall (K. Gardner) and 600 at Gimli (J. Weshnoweski) on 18 August 1995. Concentrations continue to be reported from time to time. Reports of more than 100 birds are summarized in Table 2.

\section{Conclusions and Recommendations}

When surveying Common Nighthawks during fall migration, it is important to have good all-round, longdistance visibility and to track the movements of flocks in order to distinguish between feeding and actively migrating birds. Migration in southern Manitoba is often concentrated into a few days within a two-week period in mid-August to late August, whereas feeding concentrations at favoured locations, such as the Pinawa sewage lagoons, occur almost daily during that period. It is likely that many of these feeding birds stage in the area for two or more days.

Sharp peaks and both day-to-day and year-to-year fluctuations make numerical trends difficult to discern. These complicating factors are true of any bird migration data, e.g., from hawk watches, sea watches, and migrant banding stations. Daily counts of Common Nighthawks at multiple locations would perhaps improve the monitoring of population trends, but would require a large commitment of effort. Unfortunately, such counts are not amenable to "piggybacking" on other surveys, except perhaps some hawk watches. It is also unfortunate that the boreal portion of the breeding range is poorly represented in the Breeding Bird Survey (because of inaccessibility) and that the detection efficiency of the BBS for Common Nighthawks is low because of their crepuscular habits.

The decline in August concentrations of the Common Nighthawk near Pinawa from the early 1980s to the mid-1990s (Taylor 1996) did not continue during the following decade. This is consistent with the neardisappearance of local breeding birds by 1990, but a more stable source population of transient birds. Detailed analysis of the dates of concentrations also supports this conclusion. 


\section{Acknowledgments}

I thank the birders whose observations are cited in this article and Sharon Taylor for her willingness to join me on many mosquito-infested, crepuscular forays to the sewage lagoons. I also thank Christian Artuso, Rudolf Koes, and Reto Zach for their comments on a draft manuscript.

\section{Literature Cited}

Aldridge, H. D. J. N., and R. M. Brigham. 1991. Factors influencing foraging time in two aerial insectivores: the bird Chordeiles minor and the bat Eptesicus fuscus. Canadian Journal of Zoology 69: 62-69.

Brigham, R. M. 1990. Prey selection by Big Brown Bats (Eptesicus fuscus) and Common Nighthawks (Chordeiles minor). American Midland Naturalist 124: 73-80.

Brigham, R. M., and M. B. Fenton. 1991. Convergence in foraging strategies by two morphologically and phylogenetically distinct nocturnal aerial insectivores. Journal of Zoology (London) 223: 475-489.

Conservation Committee of the Society of Canadian Ornithologists-Société des ornithologistes du Canada. 2009. Aerial Insectivore Workshop - summary of meeting held March 9-11, 2009. Picoides 22(2): 22-23.

Eckert, K. E. 1986. A census of the fall migration on the north shore of Lake Superior. The Loon 58: 64-68.
Eckert, K. E., and M. Hendrickson. 1991. A record movement of Common Nighthawks [separate notes published under a single heading]. The Loon 63: 68-69.

Nicoletti, F. J. 1997. The 1997 migration at Hawk Ridge. The Loon 70: 105-108.

Sandilands, A. 2007. Common Nighthawk. Pages 308-309 in Atlas of the breeding birds of Ontario, 2001-2005. Edited by M. D. Cadman, D. A. Sutherland, G. G. Beck, D. Lepage, and A. R. Couturier. Bird Studies Canada, Environment Canada, Ontario Field Ornithologists, Ontario Ministry of Natural Resources, and Ontario Nature, Toronto.

Savignac, C., and M. Leonard. Editors. 2007. Assessment and status report on the Common Nighthawk Chordeiles minor in Canada. Committee on the Status of Endangered Wildlife in Canada, Ottawa.

Sibley, D. A. 2000. National Audubon Society: the Sibley guide to birds. Alfred A. Knopf, New York.

Taylor, P. 1983. Wings along the Winnipeg: the birds of the Pinawa-Lac du Bonnet region, Manitoba. Eco Series (2), Manitoba Naturalists Society, Winnipeg, Manitoba (reprinted with minor revisions, 1985).

Taylor, P. 1993. Migration of Bonaparte's Gull, Larus philadelphia, in southeastern Manitoba. Canadian FieldNaturalist 107: 314-318.

Taylor, P. 1996. Apparent decline of migrant Common Nighthawks near Pinawa, Manitoba. Blue Jay 54: 35-38.

Received 23 September 2009

Accepted 2 May 2010 